Review

\title{
Biogasoline: An out-of-the-box solution to the food-for-fuel and land-use competitions
}

\author{
S.N. Hassan ${ }^{\text {a,b }}$, Y.M. Sani ${ }^{\text {a,c }}$, A.R. Abdul Aziz ${ }^{\text {a,* }}$, N.M.N. Sulaiman ${ }^{\text {a }}$, W.M.A.W. Daud ${ }^{\text {a }}$ \\ ${ }^{a}$ Department of Chemical Engineering, University of Malaya, 50603 Kuala Lumpur, Malaysia \\ ${ }^{\mathrm{b}}$ Faculty of Chemical \& Natural Resources Engineering, University Malaysia, 26300 Pahang, Malaysi \\ 'D Department of Chemical Engineering Ahmadu Bello University, 870001 Zaria, Nigeria
}

\section{A R T I C L E I N F O}

\section{Article history:}

Received 31 December 2013

Accepted 17 September 2014

Available online 23 October 2014

Keywords:

Biogasoline

Bioethanol

Biodiesel

Food-for-fuel

Microalgae

Rubber seed oil

\begin{abstract}
A B S T R A C T
Societal developments are hinged on the energy supplied by fossil fuels. However, the supply of these fuels is finite in the foreseeable future. This is aside the associated environmental degradation and economic sustainability of these fuels. These negative consequences and challenges spurred the search for sustainable energy sources such as biofuels. However, affordable feedstocks and efficient synthesis for renewable fuels remain indispensable and yet challenging line of research. Therefore, breakthroughs in plant biotechnology and mass production are essential prerequisites for ensuring the sustainability of biofuels as alternatives to petroleum-based energy. Conversely, public outcry concerning the foodfor-fuel conflicts and land-use change hinder the popularity of such biofuel energy sources. Therefore, this paper reviewed the prospects of biogasoline production as sustainable alternative to ethanol and a compliment to biodiesel. Apart from reduction in greenhouse gas emissions, biogasoline promises to be cheaper and more environmental friendly. Further, inedible feedstocks such as microalgae and rubber seed oil would ensure higher net energy gain. Consequently, these will help resolve the food-for-fuel conflicts and land-use competitions. However, achieving the biofuel central policy depends on advances in processing the renewable energy sources.
\end{abstract}

Contents

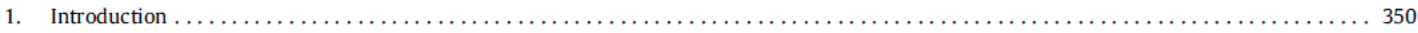

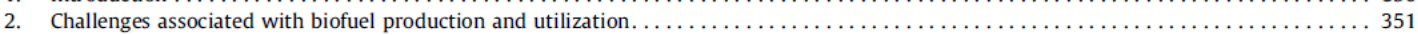

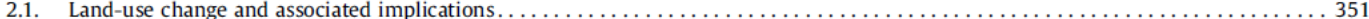

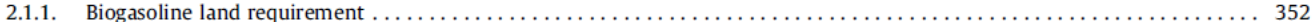

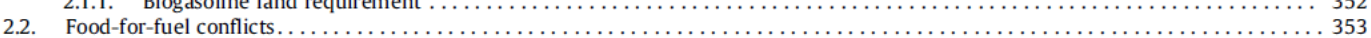

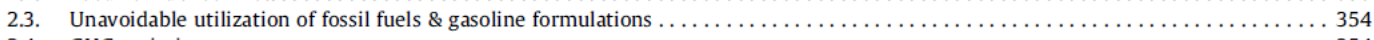

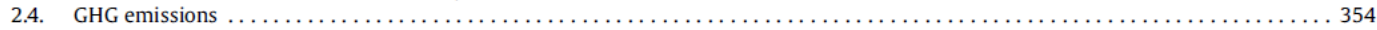

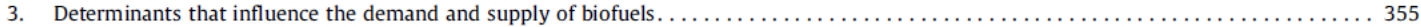

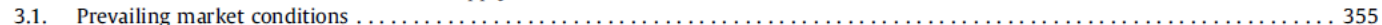

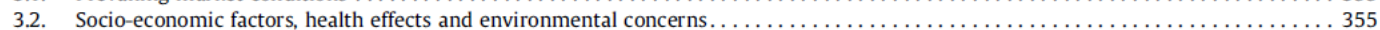

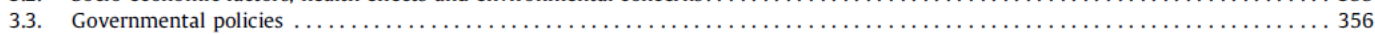

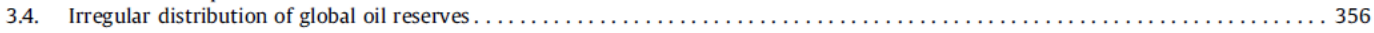

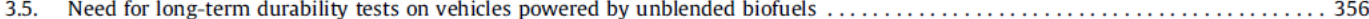

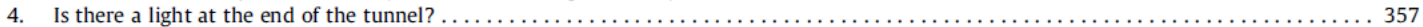

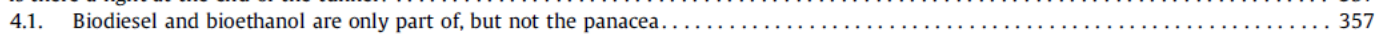

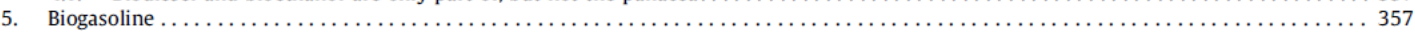

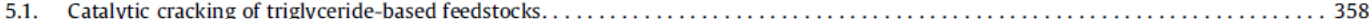

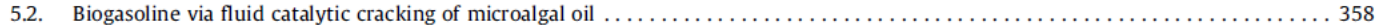

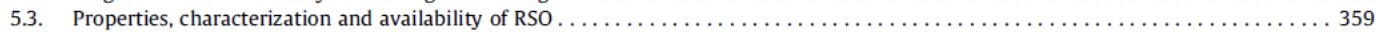

* Corresponding author. Tel.: +60 37967 5300; fax: +60 379675319 .

E-mail address: azizraman@um.edu.my (A.R. Abdul Aziz).

http://dx.doi.org/10,1016/j.enconman.2014.09.050

0196-8904/○ 2014 Elsevier Ltd. All rights reserved. 


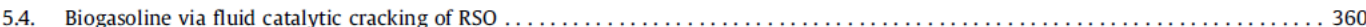

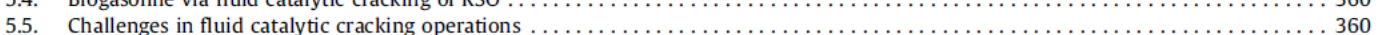

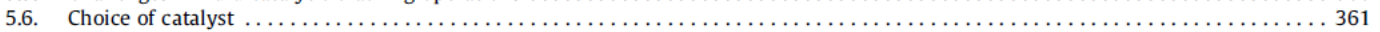

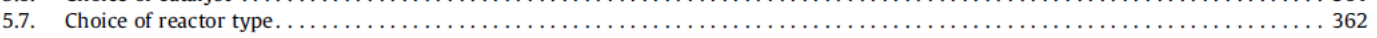

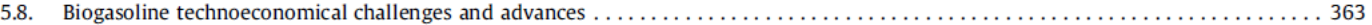

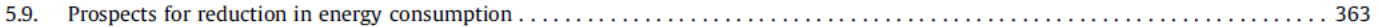

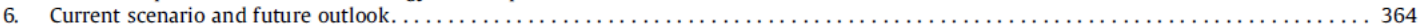

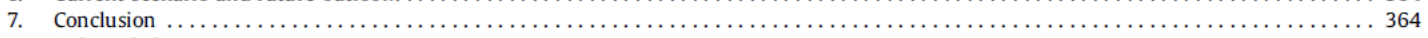

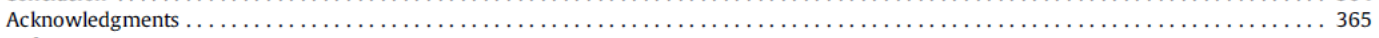

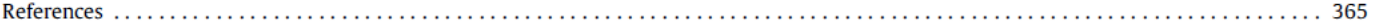

\section{Introduction}

Apprehensions over diminishing oil reserves, increasing oil prices, deteriorating health standards because of greenhouse gas (GHG) emissions and associated environmental impacts have made biodiesel emerge as the fastest growing industry worldwide [1]. It is the second most abundant combustible renewable fuel. This is because of the renewable and potentially inexhaustible source of vegetable oils $[2,3]$. Also, the energy content obtained therefrom is comparable to that of diesel fuel (Fig. 1 and Tables 1 and 2). However, to remain sustainable, some argue that nonfood crops which require minimal cultivation should be the main sources for biofuel production. Such cultivation should not compete with other feedstocks over arable land or cause deforestation. These include bioethanol from fermentation of sugarcane juice and starch-based feedstocks and biodiesel from transesterification of vegetable oil triglycerides (TGs). These issues raised the questions of food availability and prices, land-use and land-use changes, environmental degradation and socio-economic implications [4] The proponents of this view claim the extensive utilization of seed crops and vegetable oils may cause starvation especially in the developing countries. Further, a general issue that affects the global biofuel development is the high cost of feedstock which constitutes more than $88 \%$ of the overall costs [1].

Bioethanol and biodiesel are the two globally acclaimed liquid biofuels that have the potentials for replacing gasoline and diese fuels respectively. However, numerous challenges await the ingenuity of the research community and economic leeway from the policymakers. Collaborative efforts from these communities are vital in achieving the biofuel central policy especially in replacing fossil fuels, protecting and creating jobs, and protecting the environment [6]. While the research communities need to provide solutions to the production technologies and transition from fossil

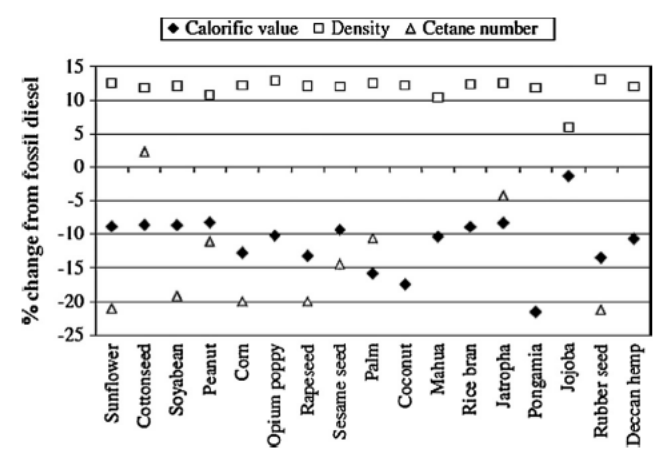

Fig. 1. Edible and inedible properties of plant oil compared to petrodiesel [5]. to biofuels, tackling the implications of such transitions rests on the policymakers. Interestingly, the need for concerted efforts and cheaper feedstocks persists [6,7]. This is despite the numerous developmental strides achieved such as utilization of abundant, affordable, and sustainable sources since Rudolf Diesel's vegetable oil dream. These strides were facilitated by advances in rational catalyst design and biotechnology. These techniques facilitate strategies for designing optimal biocatalysts and engineering native and de novo pathways for the sustainable production of biofuels. Other strides include reduced GHG emissions by $78 \%[6]$ while the Mcgyan Process ${ }^{\otimes}$ [8] produces biodiesel within $4 \mathrm{~s}$ by utilizing inexpensive, non-food-grade and FFAs-containing feedstocks.

The challenge in rapidly and efficiently switching from utilizing the 'ready-to-use' energy sources (natural gas, coal and crude oil) to the renewable energy sources is an arduous one. This challenge is more pronounced especially when considering how to avoid deforestation while promoting bioenergy. Furthermore, the energy density of E85 (76,300-84,530 Btu/gal) is lower than that of gasoline (116,090-124,340 Btu/gal) based on location, time of year and political climate (Table 2). Additionally, this value equates to 73 $83 \%$ the heat content of gasoline which gets lower in winter months in cold climates. Besides, the cost of bioethanol $\$ 3.41$ gal) is comparable to that of gasoline ( $\$ 3.65 / g a l) ~[11,12]$. Thus, spreading the perceived risks over wide range of renewable energy sources becomes appropriate. This will help provide a cocktail of energy sources which might appeal to the different needs of the consumers just like the fossil sources. Further, a diverse portfolio of energy is more likely to meet the high levels of future energy demands. Therefore, it is essential to understand and fully realize the causes that determine technological development. This is because process of developing a technology is not precise due to availability of different routes for such developmental stages. These include (a) minimal capital cost and investment, (b) utilization of affordable feedstocks, (c) environmental performance and (d) energy efficiency. Therefore, an out-of-the-box idea necessitates employing least-resistance-path approach in developing biogasoline expansion. This approach combines existing technologies and experiences with cheap resources. Though it might be below optimum initially, the approach ensures easy commercialization with minimum risks. This does not negate recognizing and promoting various 'nonbio' alternatives which are affordable, available, renewable and low-carbon alongside bioenergy [10]. Within this broader approach, bioalcohol (fermentation of sugars), biodiesel (transesterification of TGs) and bio-oil (pyrolysis of biomass) have received extensive experimentations. Similarly, the process that is gaining the attention of the academic and research communities is catalytic cracking of inedible oil to biogasoline.

Currently, ethanol is the available commercial biofuel. However, as mentioned earlier, because of sustainability, food security and economic competitiveness, it is imperative to find alternative sources. The present-day primary feedstocks such as starch 
Table 1

Comparison of common fuels used for propelling gasoline-powered vehicles $[9,10]$.

\begin{tabular}{lllllll}
\hline Fuel & Energy density, MJ/L & Air-fuel ratio & Specific energy, MJ/kg & Heat of vaporization, MJ/kg & RON $^{\mathrm{a}}$ & MON $^{\mathrm{b}}$ \\
\hline Gasoline & 34.6 & 14.6 & 46.9 & 0.36 & $91-99$ & $81-89$ \\
Butanol fuel & 29.2 & 11.2 & 36.6 & 0.43 & 78 \\
Ethanol fuel & 24.0 & 9.0 & 30.0 & 0.92 & 129 \\
Methanol fuel & 19.7 & 6.5 & 15.6 & 1.2 & 102 \\
\hline
\end{tabular}

a Research octane number.

${ }^{b}$ Motoring or Machinery octane number.

Table 2

Gasoline energy content compared to different biofuels $[11,12]$.

\begin{tabular}{llll}
\hline Fuel & MJ/L & BTU/L & Liter gasoline \\
\hline Petrogasoline & 32 & 30,336 & 1.00 \\
Biodiesel & 33.3 & 31,568 & 1.04 \\
Petrodiesel & 40.3 & 38,204 & 1.25 \\
Biobutanol & 29.2 & 27,682 & 0.91 \\
Bioethanol & 19.6 & 18,581 & 0.61 \\
\hline
\end{tabular}

Table 3

Some oil bearing plants and their oil productivity figures $[5,6]$.

\begin{tabular}{llr}
\hline Common name & Latin name & Productivity, kg oil/ha \\
\hline Palm & Erythea salvadorensis & 5652 \\
Corn & Zea mays & 145 \\
Rubber seed & Hevea brasiliensis & 217 \\
Cotton & Gossypium hirsutum & 273 \\
Deccan hemp & Cannabis sativa & 305 \\
Soybean & Glycine max & 375 \\
Linseed & Linum usitatissimum & 402 \\
Mustard & Brassica alba & 481 \\
Sesame & Sesamum indicum & 585 \\
Safflower & Carthamus tinctorius & 655 \\
Sunflower & Helianthus annuus & 800 \\
Peanut & Arachis hypogaea & 890 \\
Opium poppy & Papaver somniferum & 978 \\
Rapeseed & Brassica napus & 1000 \\
Olive & Olea europaea & 1019 \\
Jojoba & Simmondsia chinensis & 1528 \\
Babassum palm & Orbignya martiana & 1541 \\
Jatropha & Jatrpha curcas & 1590 \\
Coconut & Cocos nucifera & 2260 \\
Pongamia & Pongamia pinnata & 2500 \\
\hline
\end{tabular}

(cassava and potatoes), grains (corn, wheat and milo) and sugar (sugarcane and beet) for bioethanol production are all food sources. The feasibility of cracking the said alternatives catalytically is more than three decades old [14]. Further, the thermochemical technologies currently in use in most refineries are suitable for converting seed-oil and biomass into biogasoline. Moreover, the cost associated with engine modification is minimal because biogasoline has similar properties to conventional gasoline [15]. Other important characteristics of biogasoline include: (a) pure (100\%) biogasoline or BG100 runs in any conventional gasoline engine. (b) It substitutes petroleum-based gasoline because of similar properties. (c) It is employed in high concentrations in conventional gasoline engines unlike ethanol. (d) Biogasoline eliminates the need to build new biofuel infrastructures for conversion, storage and transportation systems. (e) Biogasoline has higher energy content and is more fuel efficient than ethanol. Nonetheless, we are of the conviction that the panacea cannot come from a single biofuel source. Consequently, the aforementioned issues require an "out-of-the-box-solution". These include incorporating other sources aside biomass, sludge and wastes into one catalytic process. Thus, we advocate pertinence in developing and applying broader and more integrated sustainability criteria that encompass not just biofuels, but other renewable sources. This is because the options available for promoting sustainability are not mutually exclusive. Therefore, considerations should be given to all feasible renewable energy sources which have the potential for long-term economic viability and minimal environmental impacts. These concerted efforts should be implemented sooner than later while ensuring continuity and consistency. Therefore, this article reviewed the economic potentials of a holistic approach to biogasoline development especially from inedible feedstocks (Sections 45). It specifically highlighted a general theme on the need for an integrated set of solutions and the potentials of microalgal and rubber seed oil (RSO) in providing solutions to the food-verses-fuel issues (Table 3). For brevity, we encourage the reader to consider all renewable sources of energy in the same respect for achieving a sustainable energy supply. Therefore, since the aim is to think out-of-the-box; the review also put into cognizance the important role that technological advancements, political influences and socio-economic situations will have to play (Sections $2-3$ ). Consequently, because of envisaged short-term fluctuations in market conditions, the review advocates for a steady approach which targets the long-term end returns.

\section{Challenges associated with biofuel production and utilization}

Energy plays significant role in the economic growth of any country. Incidentally, the US manufacturers' market share witnessed a major decline from 2002 to 2007. These and other concerns regarding climatic changes, economic constraints and efforts aimed at reducing oil imports have heightened the debates by policymakers over decreasing gasoline utilization $[16,17]$. In fact, according to most economists, the demand for gasoline has limited short-term price elasticity. Veer [18] summarized these shortcomings as the "three-hard-truths" the growing populace is experiencing. These are: (a) growing energy demand, (b) depleting gas fields and oil reserves and (c) environmental impact accruing from GHG emissions. Expectedly, the current global demand for liquid fuels will reach $118 \mathrm{mmbls} / \mathrm{d}$ in 2030 with an average increase of $1.3-1.4 \%$ per annum. The potential benefits from the transition towards the biofuel economy are not peculiar to the industrialized countries alone. In fact, the developing countries stand to benefit as much if not much more. However, these countries have to deal with the major dilemma that comes with this transition. These include how to invest in the biofuel research and development and the challenges posed by the pace of this growth as well as its enormous scale. These countries have to decide whether to invest in developing cutting edge technologies or portable user-friendly devices. Even more worrying is the issue of constant power supply especially in the rural areas $[19,20]$.

\subsection{Land-use change and associated implications}

The potential to save fossil energy is one of the driving factors in transiting to bioenergy economy. However, managing the potential land use change associated with producing renewable resources is prerequisite to actualizing this potential. Otherwise, pressure on 
the limited land resources might create unwarranted challenges such as carbon debt and threats to biodiversity. The issue of land use and land use change is gaining the attention of policymakers as well as the academic and research communities. This is because achieving fossil energy savings with reduced GHG emissions are essential to attaining and maintaining environmental sustainability from biofuels. Nguyen et al. [17] showed that increased energy credits derivable from substituting fossil electricity with renewable electricity and gasoline with bioethanol have the potential for fossil energy savings. They claimed the magnitude of the savings is dependent on two causes. The first relies on the efficiency of an integrated system in producing energy from bagasse as wel as bioethanol from the sugar. The second depends on the efficient recovery of the spent ethanol from the distillery and subsequent conversion into biogas. However, the authors were quick to note that minimizing or a total avoidance of land use change because of transition to biofuel economy is essential in achieving such savings. In other words, the output volume per unit area of land (or productivity) must be commercially feasible to meet the increasing demands.

The exuberance displayed by the Brazilian sugarcane ethanol production is encouraging. Brazil produced a GHG offset credit of $13-14 \mathrm{t} \mathrm{CO}_{2} / \mathrm{ha} / \mathrm{yr}$ by $2005 / 2006$. However, converting woodland to sugarcane plantation created a carbon debt of $165 \mathrm{t} \mathrm{CO}_{2} /$ ha. Accordingly, it will take at least a 12-year period to repay this carbon-deficit. Only after such time-span is the environmental sustainability of ethanol as an eco-friendly energy source ascertained. Furthermore, threat to biodiversity is yet another consequence of expanding biofuel production on land. Ultimately, the question is whether it is possible for this transition with its concomitant expansion to create less, or possibly eliminate the pressure on land. Is it possible for agriculture to fuel and feed the world concomitantly? This is considering world energy demand will exceed 705 exajoules ( $1 \mathrm{EJ}=1018$ joules) by 2030. This requires $37 \%$ more energy than in 2008 [13]. As if these are not enough, the consequences of the continual carbon emission are worrisome. Reports by FAO [21] suggests stable global warming below $2{ }^{\circ} \mathrm{C}$ to avoid precarious effects of climate change. In fact, to avoid undesirable risks, experts warn that 2020 must be the threshold for GHG emissions. This is because there is no sector more climate-sensitive that is both affected and affects climate change like the agriculture sector. Hazardous climatic effects lead to food shortages and consequently increase the demand on bioenergy feedstocks which serve as food sources. Conversely, depending on type of feedstock and production technology, biofue expansion will reduce estimated $10-90 \%$ GHG emissions relative fossil fuels [21]. However, despite the current stipulated policy of $\mathrm{CO}_{2}$ at $450 \mathrm{ppm}$, the world would need $18 \%$ more energy in 2030 than it did in 2008 [13]. Though biofuel looks attractive, our optimism should not becloud the apparent consequences. This is because the renewability and potential for lower carbon footprint of biofuels also have opportunity costs.

Expectedly, food will be in higher demand in 2030 due to a projected world population of more than 8 billion. The consequence of this population growth will create an unprecedented burden on the natural resources. The availability and productivity of the available water and land will be competitive with attendant impact on food prices [13]. Further, prospects of this transition has the potential to trigger demands on bioresources for producing new nonenergy products such as cosmetics, health care products, paints and plastics. Evidently, a vicious circle of cause and effect is eminent from excessive pressure on agricultural land. This is because of converting areas serving as valuable carbon sinks such as peatland, savannah or rainforest. Searchinger et al. [22] argues that emissions savings obtainable from extra bioenergy production can hardly outweigh the impact from GHG emissions. Thus the arduous task is in ensuring a smooth transition to renewable fuels with minimal-carbon energy. It is necessary to achieve this without exacerbating the world hunger or stifling economic growth.

\subsubsection{Biogasoline land requirement}

Though no official data is available on suitable and available land devoted for biogasoline expansion, it is appropriate to make analysis from the average annual increase in area harvested for major biofuel feedstocks. Langeveld et al. [23] estimated the amount of land dedicated to biofuel (including co-products) production as $32 \mathrm{Mha}$. The report showed an increase of $25 \mathrm{Mha}$ in 2010 compared to 2000 (Table 4). The authors argued that earlier estimations presented ca. $40 \%$ overestimation of land requirements by ignoring ( 11 million ha) co-product generation. Further, Table 5 depicts the scenario for substituting $10 \%$ of petroleum consumption by biogasoline while Figs. $2-4$ show suitable area not classified as forested or cultivated land for selected biofuel production, average annual increase in area harvested for major biofuel feedstocks and percentage suitable land not classified as forest or cultivated land required for substituting $10 \%$ of petroleum consumption by ethanol. Interestingly, the United States consumed 150 billion gallons of gasoline in 2009 alone. This annual consumption has increased since then In fact, America requires 240 billion gallons of ethanol to substitute gasoline with corn ethanol. How ever, the US produced only 8.9 billion gallons of ethanol in 2008 [24]. This indicates the need for more acreage devoted to biogasoline expansion to meet the increasing energy needs. Hertel et al. [25] showed how market-mediated global land use changes affects biogasoline expansion in the US (Fig. 5). This scenario highlights the importance of knowing the total global land suitable and available for biogasoline production. The foregoing further buttress the general theme of this review in exploring out-of-the-box ideas for ensuring sustainable biogasoline expansion.

Table 4

\begin{tabular}{|c|c|c|c|c|c|c|}
\hline Region & $\begin{array}{l}\text { Increased land } \\
\text { requirement }\end{array}$ & $\begin{array}{l}\text { Associated with } \\
\text { co-products }\end{array}$ & $\begin{array}{l}\text { Net biofuel area } \\
\text { increase }\end{array}$ & $\begin{array}{l}\text { Changes in agricultural } \\
\text { area }\end{array}$ & $\begin{array}{l}\text { Extra harvested area } \\
\text { due to } \mathrm{MCl}\end{array}$ & $\begin{array}{l}\text { Change in } \\
\text { NHA }\end{array}$ \\
\hline USA & 11.0 & 5.9 & 5.1 & -3.5 & 10.9 & 2.3 \\
\hline EU & 6.6 & 3.2 & 3.4 & -11.5 & 3.6 & -11.2 \\
\hline Indonesia and Malaysia & 0.02 & 0.01 & 0.01 & 8.9 & 2.0 & 10.9 \\
\hline China & 2.2 & 0.4 & 1.8 & -13.4 & 20.3 & 5.1 \\
\hline Mozambique & 0.13 & 0.03 & 0.1 & 1.3 & 0.9 & 2.0 \\
\hline Global total & & & & -47.8 & 91.5 & \\
\hline
\end{tabular}

$\mathrm{MCI}=$ multiple cropping index

NHA $=$ Net Harvested Area . 
Table 5

Scenario for substituting $10 \%$ gasoline with ethanol in the transportation sector for some selected countries [26].

\begin{tabular}{|c|c|c|c|c|c|}
\hline Country & $\begin{array}{l}\text { Additional ethanol } \\
\text { required (million } \\
\text { L) }\end{array}$ & $\begin{array}{l}\text { Proportion of harvest to meet } \\
\text { ethanol target - cane juice } \\
\text { route }^{\mathrm{b}}(\%)\end{array}$ & $\begin{array}{l}\text { Proportion of harvest to meet } \\
\text { ethanol target - A-molasses } \\
\text { route }^{\mathrm{b}}(\%)\end{array}$ & $\begin{array}{l}\text { Proportion of harvest to meet } \\
\text { ethanol target - C-molasses } \\
\text { route }^{\mathrm{b}}(\%)\end{array}$ & $\begin{array}{l}\text { Area required (ha) for } \\
\text { dedicated } \\
\text { plantations }^{c}\end{array}$ \\
\hline Argentina & 731.6 & 36.6 & 105.5 & 304.8 & 164,317 \\
\hline Guatemala & 159.6 & 9.4 & 27.1 & 78.3 & 35,834 \\
\hline Peru & 151.6 & 24.6 & 70.8 & 204.7 & 30,315 \\
\hline Philippines $^{\mathrm{a}}$ & 476.2 & 26.9 & 77.3 & 223.2 & 107,062 \\
\hline Thailand $^{\mathrm{a}}$ & 783.2 & 14.2 & 50.6 & 118.4 & 156,639 \\
\hline Vietnam & 544.8 & 50.6 & 145.9 & 421.5 & 122,355 \\
\hline Mozambique & 18.1 & 11.0 & 31.8 & 92.0 & 4058 \\
\hline Tanzania & 41.4 & 26.1 & 75.4 & 217.8 & 9293 \\
\hline Zambia & 30.7 & 18.4 & 53.1 & 153.3 & 6899 \\
\hline
\end{tabular}

Note: Countries selected have a relatively well-developed domestic sugarcane sector and a low level of ethanol in their energy mix.

a Food and Agriculture Organization of the United Nations (FAO) FAOSTAT: agricultural production data. http://faostat.fao.org/site/567/default.aspx\#ancor [10 September

2010].

${ }^{b}$ Based on sugarcane harvesting data from FAO (2010) and assuming that 75, 26 and $9 \mathrm{~L}$ can be produced per ton of sugarcane via cane juice, A-molasses and C-molasses production routes respectively.

${ }^{c}$ Area required assuming that $5000 \mathrm{~L}$ of ethanol can be produced per ha under sugarcane cultivation.

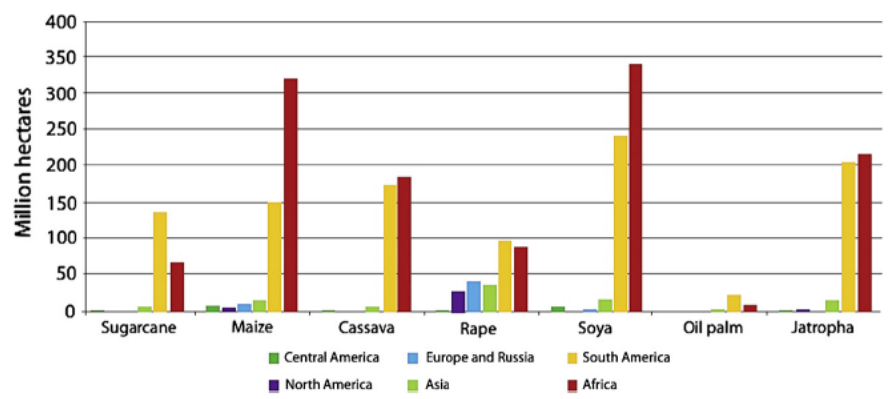

Fig. 2. Area of suitable land (not classified as forest or cultivated) for selected biofuel feedstocks [26].

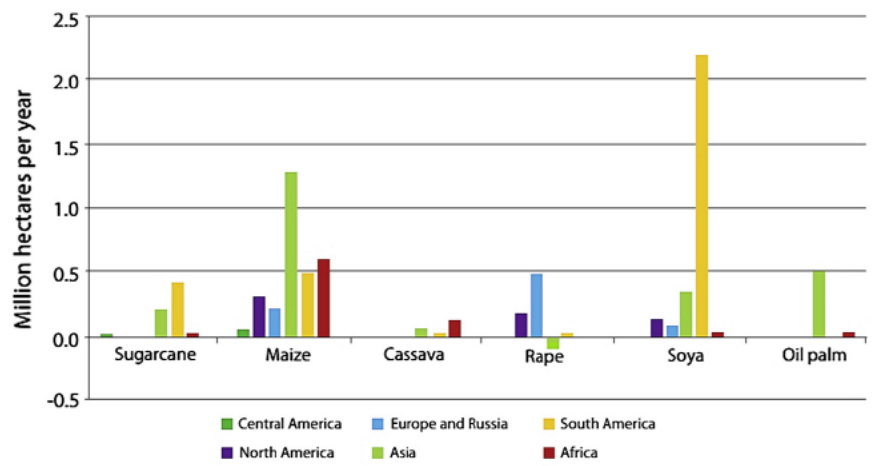

Fig. 3. Average annual increase in area harvested for major biofuel feedstocks (2000-2008) [26]. Note: Jatropha is not included as no official data on its cultivation are maintained.

\subsection{Food-for-fuel conflicts}

It is unfortunate to see this debate linger for so many years with much disagreement even amongst same ranks of the same sector. Sometimes, interests rather than prudent use of such resources play major role in the perceptions of both proponents and opponents to this issue. For instance, sales from biofuel feedstocks rather than food are more profitable to the agro-business companies. Conversely, many groups and individuals opined of negative conse- quences such as food shortages largely in developing countries. However, countries like India, China, Brazil, Indonesia and Malaysia are demonstrating the possibility for realizing the biofuel potentials on economic growth, environmental impacts and energy security. Ethanol (Brazil and US) is the dominant biofuel followed by biodiesel (Europe and Asia) $[19,27,28]$. These biofuels account for more than $80 \%$ of total biofuel production. However, some quarters argued that these expansions will lead to increase in deforestation and deterioration of peatlands and wetlands, food prices and $\mathrm{CO}_{2}$ 


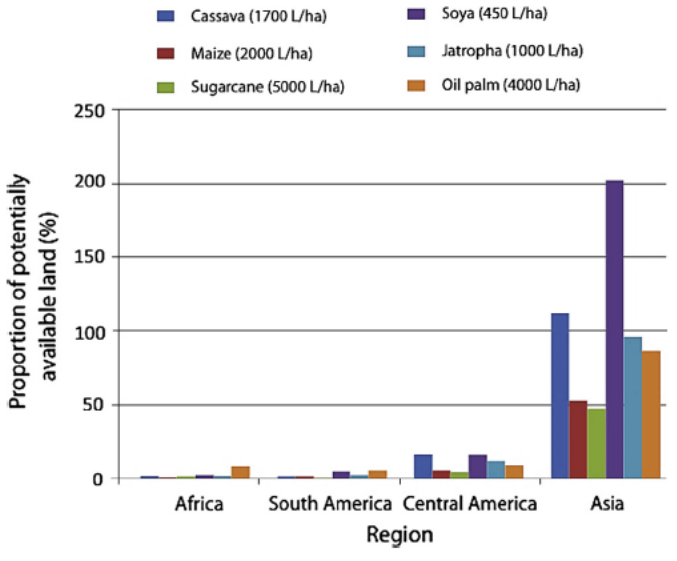

Fig. 4. Area of suitable land (not classified as forest or cultivated) for selected ethanol and biodiesel feedstocks required for substituting $10 \%$ of petroleum consumption in the transportation sector [26]. Note: Brazil was excluded from the South America ethanol figures because it has higher blending mandates than use in these scenarios.

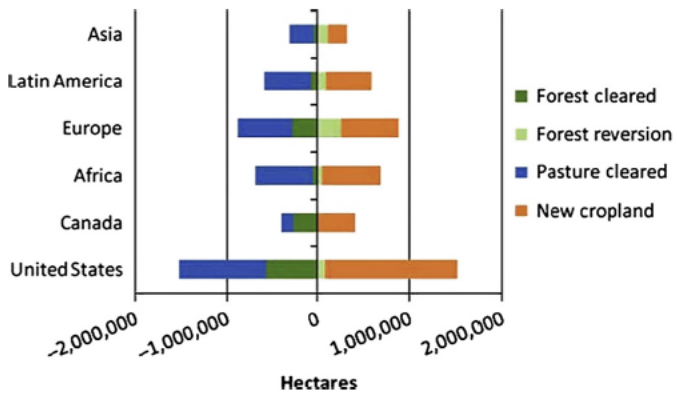

Fig. 5. Global (regional) land conversion due to increased maize ethanol production of 50.15 gigaliters per year at 2007 yields [26].

emissions. This is because of uncertainties surrounding the sustainability of biofuel production level achievable by 2050 [28]. The proponents of this rationale are therefore calling for a global concept in tackling the perceived concerns. However, a different reasoning exists between these two extremes. This group opined that with proper implementation of the right governmental policies, it is possible to source food and fuel from the same feedstock. This is because most governments have the wherewithal to provide sufficient and affordable food to their populace while concomitantly producing biofuel [28]. Notwithstanding these arguments, numerous proposals on how to alleviate the impending food shortages are available [29]. These include experimenting inedible alternative feedstocks such as microalgae oil [30], Jatropha, miscanthus, used cooking oil and free fatty acid mixtures. Similarly, the Food and Agriculture Organization (FAO) of the United Nations considered the prospects of microcredit system in biofuel economy especially by the rural and subsistence farmers [31,32].

2.3. Unavoidable utilization of fossil fuels \& gasoline formulations

The current estimated worldwide fuel consumption is $62 \%$ with substantial projected increase [1]. To date, most production of bio- energy still relies on energy produced from fossil fuels such as (premium motor spirit, kerosene and diesel), natural gas and coal. Therefore, any net energy savings derivable from the biofuel economy is dependent on the extent of the reliance on fossil fuel energy usage [17]. These led to the search for immediate solutions as viable source of energy and means of reducing GHG emissions. A common practice that is gaining the attention of automobile research is the use of gasoline formulations with oxygenated compounds. This improves the gasoline quality by increasing the octane rating and reducing $\mathrm{CO}$ and unburned hydrocarbon emissions. Similarly, increasing automobile engine thermal efficiency is another technically viable means of reducing $\mathrm{CO}_{2}$ [33]. However, these solutions are only the beginning in the myriad of challenges as they necessarily require the use of fossil fuels in larger percentages.

Historically, ethanol was the main fuel for propelling automobiles since the late $1800 \mathrm{~s}$. As at then, the prospects envisioned for ethanol was much greater than transportation. However, development of the petroleum industry marred such potential utilization from becoming reality. The multifaceted concerns from utilizing petroleum-based fuels have made the re-emergence of bioethanol possible. According to U.S. Department of Energy [34], it is possible to run all automobile engines produced after 1988 with E10 (mostly up to E20) ethanol-alcohol blends without problem. Notwithstanding its lower energy density, ethanol has 35$40 \%$ higher octane rating, thermal efficiency and has the potential for improving engine performance than pure gasoline. Encouragingly, utilizing ethanol as blend in gasoline as well as a sand-alone fuel is becoming the norm. In fact, thirteen out of the 134 billion gallons (about $10 \%$ by volume) of gasoline consumed in 2012 by the US was ethanol. Further, current US cornstarch production capacity accounts for more than $95 \%$ ethanol used as E10. However, this is nowhere near the 38 billion liters p.a. and ca. $6 \%$ automobile consumption [35]. Incidentally, Solomon et al. [35,36 showed that without subsidies, cost-competitive cellulosic ethanol is possible from cheap feedstock and high biomass conversion efficiencies.

Conversely, other analyses via different assumptions alluded to opposing conclusion [37-40]. Nonetheless, a contingent valuation reported by Solomon et al. [41] showed that most consumers from north-central states of US are willing to pay extra to develop biofuel in the short-term. Also, to attain competitive edge over conventional gasoline as a blend or fuel, certain challenges need resolving. These include the unavoidable anti-fuel properties such as moisture, high flash point and lower heat of combustion inherently present in ethanol. Lower energy density $(24.0 \mathrm{MJ} / \mathrm{L})$ which is approximately $68-75 \%$ compared to $32-35 \mathrm{MJ} / \mathrm{L}$ of gasoline $[32,42]$. Adding denaturant to the ethanol fuel usually minimize these limitations. However, the energy derived from the consequent ethanol fuel formulated has ca. 33\% less energy than its unblended gasoline counterpart depending on the amount added (Table 1). For instance, the total mileage expected from an engine run by $10 \%$ ethanol blended gasoline (E10) is up to $3.3 \%$ less [19]. Though modification of most engines not designed to run on ethanol requires only a few thousand dollars, corrosion, deterioration, and breakdown of some rubber, plastic and metal components remains major challenges. This is because during engine design, specifications were for fossil fuels not on ethanol/gasoline blends or pure ethanol [43]. This further highlights the potential advantages of biogasoline.

\subsection{GHG emissions}

A critical analysis of engine emission data reveals the need for urgent solutions. This explains the clarion-call by UN SecretaryGeneral during COP19 climate conference. He warned that the catastrophe in Philippines was enough for the world to

\section{Link to Full-Text Articles :}

http://umexpert.um.edu.my/file/publication/00003241 111377.pdf

http://www.sciencedirect.com/science/article/pii/S0196890414008516 